Original Article (short paper)

\title{
Association between insufficient level of physical activity and multiple health risk behaviors in adolescents
}

\author{
Lucas Souza Santos $^{1,2} \mathbb{E}^{-}$, Davi Soares Santos Ribeiro ${ }^{1,3}{ }^{\infty}$, Íkaro Daniel Carvalho Barreto ${ }^{5}$, \\ Vitor Hugo Fernando de Oliveira ${ }^{6}$, Danilo Rodrigues Pereira da Silva ${ }^{4}$, Aldemir Smith Menezes ${ }^{1,4,7}$

\begin{abstract}
${ }^{1}$ Grupo de Pesquisa em Educação Física e Saúde, Itabaiana, SE, Brasil; ${ }^{2}$ Secretaria de Educação básica do Município BA, Brasil; " ${ }^{4}$ Universidade Federal de Sergipe, Programa de Pós-Graduação em Educação Física, São Cristóvão, SE, Brasil; ${ }^{5}$ Universidade Federal Rural de Pernambuco, Programa de Pós-Graduação em Biometria e Estatística Aplicada, Recife, PE, Brasil; ' ${ }^{6}$ niversidade Estadual de Londrina, Programa de Pós-graduação em Educação Física, Londrina, PR, Brasil; ; Instituto Federal de Educação, Ciência e Tecnologia de Sergipe, Itabaiana, SE, Brasil
\end{abstract} \\ de Aracaju, Aracaju, SE, Brasil; ${ }^{3}$ Centro Universitário AGES, Faculdade de Ciências Humanas e Sociais, Paripiranga,
}

\begin{abstract}
Aim: To verify the association between insufficient level of physical activity and multiple health risk behaviors (HRB) in adolescents. Methods: This is an epidemiological study with cross-sectional design carried out in 2016 with 3,617 adolescents aged 14-19 years and enrolled in the public-school system of Sergipe, northeast Brazil. Data were collected using the Global School-based Student Health Survey (GSHS/WHO). The insufficient level of physical activity was defined as not achieving at least 60 minutes of moderate to vigorous physical activity for 5 days a week. The HRB analyzed were smoking, alcohol consumption, low fruit consumption and exposure to sedentary behavior. The analysis of prevalence odds ratio was used to identify the association between insufficient level of physical activity and HRB, as well as unadjusted and adjusted binary logistic regression for the association between socioeconomic and demographic variables. Results: The prevalence of insufficient level of physical activity was $83.3 \%$. There was association between physical inactivity and low fruit consumption and alcohol consumption $(\mathrm{p}<0.001)$. Insufficient level of physical activity was also associated with female sex (OR=1.90, 95\% CI, 1.56-2.32), family income of up to 2 minimum wages $(\mathrm{OR}=1.57,95 \% \mathrm{CI}, 1.17-2.11)$, maternal schooling less than 8 years $(\mathrm{OR}=1.55,95 \% \mathrm{CI}, 1.28-1.86)$ and exposure to two different HRB at the same time $(\mathrm{OR}=1.76,95 \% \mathrm{CI}, 1.27-2.45)$. Conclusion: The prevalence of insufficient level of physical activity is high and was associated with multiple HRBs in this understudied population. These findings may support interventions focusing on the cluster of risk behaviors in youth.
\end{abstract}

Keywords: motor activity, sedentary lifestyle, simultaneity, adolescents.

\section{Introduction}

Evidence has highlighted the insufficient level of physical activity as one of the main health risk factor ${ }^{1-2}$, including negative effects on vascular outcomes ${ }^{3}$, metabolic diseases ${ }^{4}$ and some types of cancers $^{5}$. International estimates have indicated that these diseases account for millions of deaths worldwide and, if the insufficient level of physical activity was decreased, these deaths could be prevented ${ }^{1}$. In Brazil, the level of physical activity among young people is below international recommendations, which recommend 60 minutes daily of moderate to vigorous physical activity for at least 5 days per week to obtain health benefits ${ }^{6}$. The National Student Health Survey (PeNSE) pointed out that only $20 \%$ of young Brazilians reach this recommendation ${ }^{7}$

In addition to their direct negative effects ${ }^{1}$, some evidence has shown that the insufficient level of physical activity may be clustered with more than one health risk behavior (HRB) ${ }^{8}$ at the same time in adults and youth ${ }^{8-10}$. In Brazil, this may be worrying for some reasons. Firstly, a high prevalence of insufficient level of physical activity was observed in adolescents throughout the Brazilian national territory ${ }^{7,11}$. Secondly, there are reports of an increasing aggregation of different HRB among Brazilian adolescents in recent years ${ }^{9}, 12$, including exposure to alcohol consumption, smoking, sedentary behaviors and low fruit consumption which, in aggregate, may increase health risks ${ }^{10}$.

Although the harm of exposure to insufficient level of physical activity is very extensive in literature ${ }^{1}$, little is known about the joint exposure of this behavior with alcohol consumption, smoking, sedentary behavior and low fruit consumption in adolescents from specific sociocultural contexts. Thus, this study aimed to verify the association between insufficient level of physical activity and multiple HRB (alcohol consumption, smoking, sedentary behavior, and low fruit consumption) and related factors in adolescents from the State of Sergipe, in Northeast Brazil. We hypothesized that insufficient levels of physical activity are associated to other HRB in this population. 


\section{Method}

\section{Study design}

The current study is part of a broad epidemiological survey with a cross-sectional design titled "Secular trend on health risk behaviors in adolescents: CRiS_adolescentes study". The study received approval from the Ethics Research Committee of the Federal Institute of Education, Science and Technology (IFS) under the number 1522.876/2016/CEP/CONEP/CNS.

\section{Sample}

The population was composed of 14 to 19 year-old school adolescents of both sexes, enrolled in the day and night shifts of the state public school system during the year of 2016. Considering data available in the State Department of Education, high school enrollment was 60,548 students ${ }^{13}$. The enrollment number represented about $80 \%$ of high school students across the state. Some criteria were adopted for the sample composition. First, schools were selected according to the number of students, distributed in municipalities in each territory. Next, classes were randomly selected by grades and shift that would be used in data collection. To perform the sample calculation, the complex sampling process available in SPSS software was used (version 15).

For the general project, some criteria were adopted for estimating sample size. The first one was to consider the population size, the estimated prevalence of $50 \%$ as the maximum expected, $95 \%$ confidence interval, and tolerable sample error of 5\%. Because it is a sample process per cluster, the sample size was multiplied by 1.5 as a function of the correction of the design effect (def $=1.5)$, estimating the need of student for each territory (StatCal.Epiinfo). In order to account for sample loss, $20 \%$ of school adolescents were added for several reasons, such as: not being present on the day of data collection, refusal to participate, age different from criteria established in the study and not answering important questions such as sex or age.

For this study, an association analysis was used, respecting statistical power of $80 \%$ and the odds ratio of 1.2 requiring a minimum sample of 3,875 adolescents. These criteria were adopted because of the lack of information on the prevalence of the different variables that would be investigated. The two-stage stratified sampling process was used in the sample selection: a) The stratified sampling process proportional to the territory and size of the teaching unit was used ( $1=$ up to 199 students, $2=200-499$ students, $3=500+$ students), according to criteria of the "Anísio Teixeira" National Institute of Studies and Educational Research (INEP) ${ }^{14}$. Thus, in order to ensure that all territories were representatively surveyed, respecting territories established in the research, a $25 \%$ draw of the state teaching units (160 schools) was established surveys, totaling 42 schools in 30 municipalities; and b) Classes were selected, according to grade and study shift, using a simple random process, considering an average of 20 students per class.
The consent term was used, respecting the anonymous and voluntary participation of students in the research. In addition, other criteria were established: to be properly enrolled in the $1^{\text {st }}$ to $3^{\text {rd }}$ grade of selected High Schools; presence at the time of application of the data collection instrument; adequately fill in the distributed questionnaire, duly marking the questions on the answer sheet with the established colors (blue or black); to be aged 14-19 years. Data were collected by Physical Education professionals properly trained in the domain of the questions of the instrument, form of application, support and conference of answers. Questionnaires were applied on a school day, in the classroom, with the presence of two professionals in each class to assist in completing the questionnaire. The instrument used was a Portuguese version of the Global School-Based Student Health Survey, proposed by the World Health Organization ${ }^{15}$. The mean time in the instrument application was 45 minutes.

\section{Dependent variable: insufficient level of physical activity}

Physical activity was obtained from an objective question: "During the last 7 days, on how many days have you been physically active for a time of 60 minutes?" Adolescents who did not perform 60 minutes of moderate to vigorous physical activity in at least 5 days in the last week were considered insufficiently active ${ }^{6}$.

\section{Independent variables}

The multiple HRB investigated consisted of: a) alcohol consumption; b) smoking; c) low fruit consumption; and d) sedentary behaviors. These behaviors were obtained from the objective questions: a) "Do you consume alcohol?" Adolescents who reported consuming alcoholic beverages were considered exposed ${ }^{16} ; \mathrm{b}$ ) "During the past 30 days, on how many days did you smoke cigarettes or other forms of tobacco?" Adolescents who reported smoking one or more days in the last 30 days were considered exposed ${ }^{17}$; c) "During the past 30 days, how many times a day did you eat fruits?" Those who consumed up to three servings of fruits per day were considered exposed ${ }^{18} ;$ d) "On a typical day, how much time do you spend sitting, watching $\mathrm{TV}$, using the computer, talking to friends, playing cards or dominoes?" Adolescents who spent 2 hours or more per day in activities in the seated position were considered exposed ${ }^{19}$.

\section{Covariates}

Sex, chronological age, study shift, place of residence, skin color, maternal schooling, family income, and main source of income were assessed as covariates.

Data were tabulated electronically, using an optical reader and the Intelligent Character Recognition-Teleform software (HS Informática, Rio de Janeiro, Brazil) and the FI-6230 scanner (Fujitsu, Tokyo, Japan). Also, a manual conference 
of questionnaires that presented problems in the electronic stage was carried out.

\section{Statistical analysis}

Data analysis was divided into four steps. The first one consisted of a descriptive analysis to verify the sample characteristics. The chi-square test was used to associate the insufficient level of physical activity with socioeconomic and demographic variables, as well as the others HRB. In the third step, the prevalence odds ratio (POR) was used to calculate the association between insufficient level of physical activity with the sum of the other HRB. Finally, unadjusted and adjusted binary logistic regression were used to verify the association between insufficient level of physical activity and multiple HRB, demographic and socioeconomic factors. In these models, the insufficient level of physical activity was adopted as covariate and sex, age, study shift, family income and main source of income were considered exposures. After the unadjusted analysis, variables with $\mathrm{p}$-value $<0.20$ were included in the adjusted model, and a p-value of 0.05 was adopted for the entire statistical treatment. For this, SPSS software for Windows (Version 15.0) was used.

\section{Results}

The questionnaires were answered by 4,721 adolescents (2,720 females and 1,980 males) in total. According to the inclusion criteria, some adolescents were excluded from the analysis as follow: those younger than 14 years old (12 subjects); those older than 19 years old (549 subjects); those who did not answered to relevant questions such as age (6 subjects) and gender (12 subjects); and those who did not present complete information about the four HRB investigated (504 subjects). The final sample resulted in 3,617 individuals, being $61.4 \%$ of females $(n=2,109)$ and $56.7 \%$ of males $(n=1,508)$. For $61.1 \%(1,734$ adolescents $)$, the family income was up to one minimum wage and the main source of income among families consisted of the work of father or mother 58.0\% (2,097 adolescents) (Table 1).

Table 1. Characteristics of the sample $(n=3,617)$, Sergipe, Brazil, 2016.

\begin{tabular}{|c|c|c|c|c|}
\hline Variable & n (\%) & Insufficient level of physical activity & $\%(95 \% \mathrm{CI})$ & p-value \\
\hline \multicolumn{5}{|l|}{ Sex } \\
\hline Male & $1,508(41.7)$ & 1,164 & $38.6(36.9-40.4)$ & \multirow[t]{2}{*}{$<0.001$} \\
\hline Female & $2,109(58.3)$ & 1,850 & $61.4(59.6-63.1)$ & \\
\hline \multicolumn{5}{|l|}{ Age } \\
\hline $14-15$ & $657(18.2)$ & 568 & $18.8(18.8-18.8)$ & \multirow[t]{3}{*}{0.059} \\
\hline $16-17$ & $1,945(53.7)$ & 1,607 & $53.3(51.5-55.1)$ & \\
\hline $18-19$ & $1,015(28.1)$ & 839 & $27.8(26.1-29.6)$ & \\
\hline \multicolumn{5}{|l|}{ Study shift } \\
\hline Day & $2,575(71.2)$ & 2,170 & $72(70.4-73.6)$ & \multirow[t]{2}{*}{0.017} \\
\hline Night & $1,042(28.8)$ & 844 & $28(26.4-29.6)$ & \\
\hline \multicolumn{5}{|l|}{ Maternal schooling } \\
\hline$\leq 8$ years & $1,807(56.1)$ & 1,552 & $58(56.1-59.8)$ & \multirow[t]{2}{*}{$<0.001$} \\
\hline$>8$ years & $1413(43.9)$ & 1,126 & $42(40.2-43.9)$ & \\
\hline \multicolumn{5}{|l|}{ Family income } \\
\hline $1 \mathrm{MW}$ or less & $2,025(59.4)$ & 1,734 & $61.1(61.1-61.1)$ & \multirow[t]{3}{*}{$<0.001$} \\
\hline $1-2 \mathrm{MW}$ & $994(29.1)$ & 812 & $28.6(27.0-30.3)$ & \\
\hline$>2 \mathrm{MW}$ & $391(11.5)$ & 291 & $10.3(8.6-12.0)$ & \\
\hline \multicolumn{5}{|l|}{ Place of residence } \\
\hline Urban & $2,072(58.2)$ & 1,681 & $56.7(54,9-58,5)$ & \multirow[t]{2}{*}{$<0.001$} \\
\hline Rural & $1,489(41.8)$ & 1,284 & $43.3(41.5-45.1)$ & \\
\hline \multicolumn{5}{|c|}{ Main source of income } \\
\hline Retirement & $477(13.2)$ & 410 & $20.6(19.7-21.6)$ & \multirow[t]{5}{*}{$<0.001$} \\
\hline Federal Benefits & $623(17.2)$ & 555 & $27.8(26.9-28.8)$ & \\
\hline Parent's work & $2,097(58.0)$ & 695 & $34.9(34-35.8)$ & \\
\hline Pension & $110(3.0)$ & 97 & $4.9(4.0-5.9)$ & \\
\hline Other & $310(8.6)$ & 236 & $11.8(11.0-12.9)$ & \\
\hline
\end{tabular}

$\mathrm{CI}=$ Confidence interval. $\mathrm{MW}=$ Brazilian minimum wage $(\mathrm{R} \$ 880)$. Data were analyzed using Chi-square tests. 
Table 2 shows the prevalence of insufficient level of physical activity and others HRB as well as the cluster of HRB: a) low exposure to tobacco $5 \%$; b) $69.2 \%$ exposure to alcohol; c) low fruit consumption $45.2 \%$; d) students exposed to sedentary behavior $64.6 \%$; e) high exposure between $1 \mathrm{HRB}$ $33 \%$ and 2 HRB $44.5 \%$.

Figure 1 shows the interrelationship between the association of insufficient level of physical activity with others HRB. Insufficient level of physical activity was associated with alcohol consumption $(\mathrm{OR}=1.48,95 \% \mathrm{CI}, 1.24-1.77, \mathrm{p}<0.001)$ and with low fruit consumption $(\mathrm{OR}=1.36,95 \% \mathrm{CI}, 1.13-1.63, \mathrm{p}=0.001)$.

Table 3 shows the association of physical inactivity with sex, family income and exposure to multiple HRB. Female students $(\mathrm{OR}=1.90,95 \% \mathrm{CI}, 1.56-2.32)$, those with family income up to two minimum wages $(\mathrm{OR}=1.57, \mathrm{CI} 95 \% 1.17-2.11)$, those with maternal schooling less then 8 years $(\mathrm{OR}=1.37,95 \% \mathrm{CI}$ 1.12-1.69) and those who are exposed to at least two $\mathrm{HRB}(\mathrm{OR}=$ $1.76,95 \%$ CI 1.27-2.45) were more likely to physical inactivity.

Table 2. Distribution of health risk behaviors among adolescents $(n=3,617)$, Sergipe, Brazil, 2016.

\begin{tabular}{|c|c|c|c|c|}
\hline Variable & n (\%) & $\begin{array}{l}\text { Insufficient level of } \\
\text { physical activity }\end{array}$ & $\%(95 \%$ CI $)$ & p-value \\
\hline \multicolumn{5}{|l|}{ Smoking } \\
\hline Yes & $193(5.3)$ & 151 & $5.0(4.3-5.8)$ & 0.051 \\
\hline No & $3,424(94.7)$ & 2,863 & $95.0(94.2-95.7)$ & \\
\hline \multicolumn{5}{|l|}{ Alcohol use } \\
\hline Yes & $2,463(68.1)$ & 2,087 & $69.2(67.6-70.9)$ & 0.001 \\
\hline No & $1,154(31.9)$ & 927 & $30.8(29.1-32.4)$ & \\
\hline \multicolumn{5}{|l|}{ Fruit consumption } \\
\hline$\leq 3$ days & $1,922(53.1)$ & 1,651 & $54.8(53.0-56.5)$ & $<0.001$ \\
\hline$>3$ days & $1,695(46.9)$ & 1,363 & $45.2(43.5-47.0)$ & \\
\hline \multicolumn{5}{|l|}{ Sedentary behavior } \\
\hline$\leq 2 \mathrm{~h} /$ day & $1,272(35.4)$ & 1,063 & $35.4(33.8-37.2)$ & 0.817 \\
\hline$>2 \mathrm{~h} /$ day & $2,345(64.6)$ & 1,936 & $64.6(62.8-66.2)$ & \\
\hline \multicolumn{5}{|l|}{ Multiple HRB } \\
\hline 0 & $331(9.1)$ & 253 & $8.4(7.5-9.5)$ & $<0.001$ \\
\hline 1 & $1,236(34.2)$ & 991 & $33.0(31.4-34.7)$ & \\
\hline 2 & $1,545(42.8)$ & 1,335 & $44.5(42.7-46.3)$ & \\
\hline 3 & $490(13.5)$ & 408 & $13.6(12.4-14.9)$ & \\
\hline 4 & $15(0.4)$ & 12 & $0.4(0.2-0.7)$ & \\
\hline
\end{tabular}

$\mathrm{CI}=$ Confidence interval. $\mathrm{HRB}=$ Health risk behaviors. Data were analyzed using Chi-square tests.

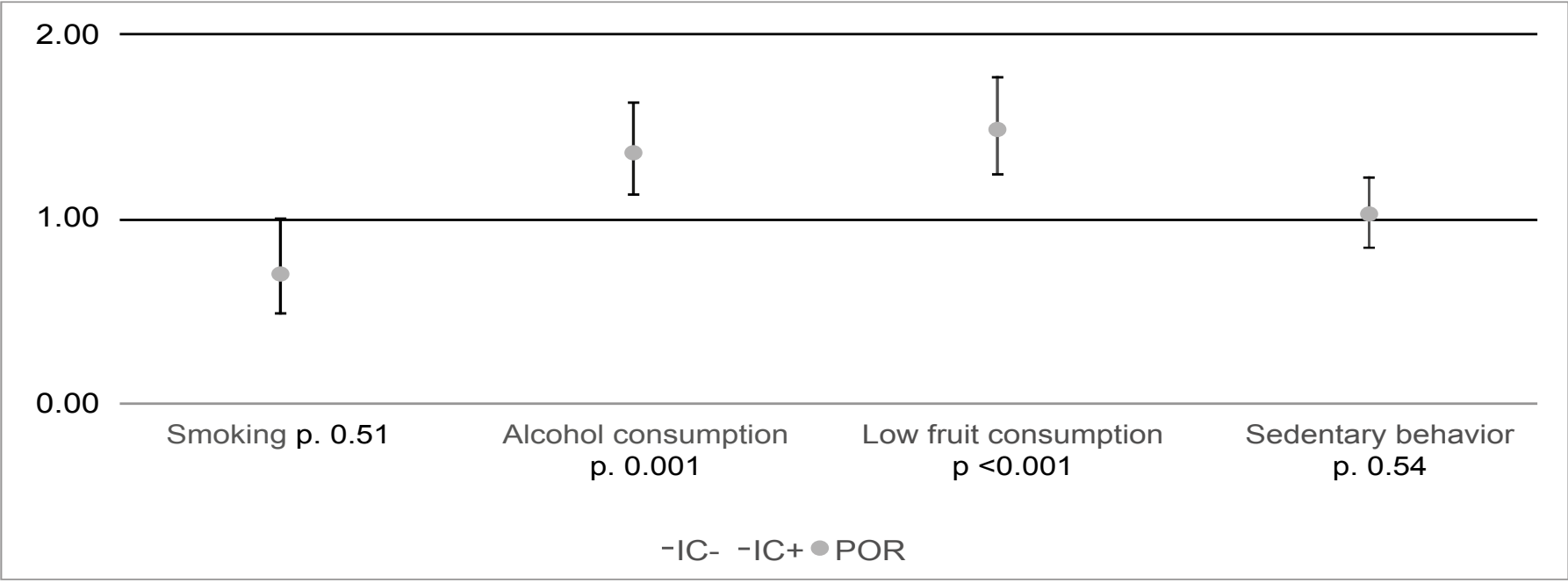

Figure 1. Prevalence Odds Ratio (POR) for insufficient level Note. CI $=95 \%$ confidence interval. "Smoking" was defined as having any amount of cigarettes in the past 30 days; "alcohol consumption" was defined as consuming alcoholic beverages; "low fruit consumption" was defined as consuming less than three servings of fruits per day; and "sedentary behavior" was defined as spending two hours or more per day in activities in the seated position. 
Table 3. Binary logistic regression to estimate the association of insufficient level of physical activity with multiple health risk behaviors in adolescents, Sergipe, Brazil, 2016.

\begin{tabular}{|c|c|c|c|c|}
\hline \multirow{2}{*}{ Variable } & \multicolumn{2}{|c|}{ Unadjusted } & \multicolumn{2}{|c|}{ Adjusted } \\
\hline & OR $(95 \%$ CI $)$ & p-value & OR (95\% CI) & p-value \\
\hline \multicolumn{5}{|l|}{ Sex } \\
\hline Male & 1 & 0.019 & 1 & $<0.001$ \\
\hline Female & $2.11(1.76-2.52)$ & & $1.90(1.56-2.32)$ & \\
\hline \multicolumn{5}{|l|}{ Age } \\
\hline $14-15$ & 1 & 0.060 & 1 & 0.101 \\
\hline $16-17$ & $1.33(1.01-1.76)$ & & $0.75(0.57-0.99)$ & \\
\hline $18-19$ & $0.99(0.81-1.21)$ & & $0.87(0.31-1.20)$ & \\
\hline \multicolumn{5}{|l|}{ Study shift } \\
\hline Day & 1 & $<0.001$ & 1 & 0.049 \\
\hline Nigtht & $1.25(1.04-1.51)$ & & $1.25(1.00-1.56)$ & \\
\hline \multicolumn{5}{|l|}{ Maternal schooling } \\
\hline$>8$ years & 1 & 0.007 & 1 & 0.002 \\
\hline$\leq 8$ years & $1.55(1.28-1.86)$ & & $1.37(1.12-1.69)$ & \\
\hline \multicolumn{5}{|l|}{ Family income } \\
\hline $1 \mathrm{MW}$ or less & 1 & 0.009 & 1 & 0.009 \\
\hline $1-2 \mathrm{MW}$ & $2.04(1.58-2.65)$ & & $1.57(1.17-2.11)$ & \\
\hline$\geq 2 \mathrm{MW}$ & $1.53(1.6-2.02)$ & & $1.34(0.99-1.80)$ & \\
\hline \multicolumn{5}{|l|}{ Multiple HRB } \\
\hline 0 & 1 & 0.008 & 1 & $<0.001$ \\
\hline 1 & $1.19(0.88-1.60)$ & & $1.02(0.73-1.41)$ & \\
\hline 2 & $1.87(1.39-2.53)$ & & $1.76(1.27-2.45)$ & \\
\hline 3 & $1.52(1.07-2.18)$ & & $1.49(1.00-2.20)$ & \\
\hline 4 & $1.15(0.37-4.20)$ & & $0.88(0.22-3.45)$ & \\
\hline
\end{tabular}

$\mathrm{OR}=$ Odds ratio. Test Hosmer-Lemeshow $=0.489 . \mathrm{CI}=$ Confidence interval. $\mathrm{MW}=$ Brazilian minimum wage $(\mathrm{R} \$ 880)$. HRB=Health risk behaviors.

\section{Discussion}

High prevalence of insufficient level of physical activity was found among adolescents from Sergipe, Brazil. Only $16.7 \%$ reached the international recommendations of physical activity for obtaining health benefits ${ }^{6}$. There was association between insufficient level of physical activity and sex, maternal schooling, alcohol consumption, and low fruit consumption. There was insufficient physical activity level with the aggregation of two and three HRB. These results confirm previous studies involving adolescents from other regions/countries.

Research conducted in China revealed that $80 \%$ of young people do not perform satisfactory physical activity for health ${ }^{4}$. Similarly, studies conducted with adolescents from public schools in Kuwait also found that only $20 \%$ of school adolescents performed 300 minutes or more of physical activity per week ${ }^{20}$. It is worth mentioning that data in the global sphere are alarming ${ }^{1,21}$, and that this evidence corroborates the international literature on "physical inactivity pandemic"22.
In Brazil, insufficient level of physical activity is the most frequent HRB among young people ${ }^{23}$. Northeast states such as Piauí (25.2\%), Sergipe (28.1\%) and Maranhão (28.2\%) stood out with the worst rates ${ }^{7}$ of insufficient level of physical activity which was usually observed in high-income countries ${ }^{24}$, but nowadays it is perceived that young people from middle- and low-income countries are less and less physically active ${ }^{25}$.

In Sergipe, the socioeconomic level was an important predictor for insufficient level of physical activity. It was found that adolescents with low schooling mothers ( $>8$ years) and family income up to two minimum wages are more likely not to reach the international recommendations of physical activity $(\mathrm{PA})^{6}$. These findings show the importance of directing interventions and public policies for underserved youth, especially in the context of low to middle-income countries ${ }^{25}$. Female adolescents were almost two times more likely to be physically inactive when compared to boys. These findings are consistent with the literature being that girls perform less physical activity than boys regardless of the evaluation method and instrument in the 
collection of information ${ }^{26}$. It is noteworthy that this prevalence follows the global trend involving the insufficient level of physical activity when stratified by $\operatorname{sex}^{24}$, and that this trend should subsidize differentiated strategies to make adolescents more active, especially girls.

Studies have shown that HRB tends to act in an associated form, that is, the exposure of one HRB can increase the risk of other ${ }^{27-28}$. Although this is not well established, it is supposed that exist a profile of adolescent who is more prone to adopt unhealthy behaviors. This is especially alarming considering the moderate tracking of some health behaviors lifelong. Thus, this subgroup should be prioritized in public health actions since early ages. In Sergipe, adolescents who do not perform 60 minutes of moderate to vigorous physical activity for at least five days a week are more likely to be exposed to alcoholic beverages. These findings were also reported in different socio-cultural realities, such as among the population of England ${ }^{27}$. There was also association between insufficient level of physical activity with eating habits, which means that insufficient levels of physical activity increase the odds of adolescents failing to meet international recommendations on fruit consumption. In agreement with previous studies conducted with adolescents from the Southern and Northeast regions of Brazil $^{10,12}$. In this way, it is noticed that the interrelationship between insufficient level of physical activity and other multiple HRB is not an isolated fact in Sergipe.

The study has limitations. The transversal design is one of them because it prevents the analysis of causality. The use of questionnaires for the assessment of insufficient physical activity level and other HRB can provide bias. However, we used a validated questionnaire for this population. The study represents the first investigation on the association between HRB in the context of Northeast Brazil adolescents based on a State representative sample.

In conclusion, our results highlighted that reducing physical inactivity is a global challenge, especially because this unhealthy habit is associated with several predictive factors, including demographic, economic, and behaviors aspects. This fact requires the conviction that the health benefits from increasing youth physical activity do not mean that adolescents reach physical activity guidelines, but rather promote actions that may minimize other HRBs in this population.

\section{References}

1. Lee I-M, Shiroma EJ, Lobelo F, Puska P, Blair SN, Katzmarzyk PT. Impact of Physical Inactivity on the World's Major NonCommunicable Diseases. Lancet. 2012;380(9838):219-29.

2. Rezende LFM, Rabacow FM, Viscondi JYK, Luiz O do C, Matsudo VKR, Lee I-M. Effect of Physical Inactivity on Major Noncommunicable Diseases and Life Expectancy in Brazil. J Phys Act Hea.1 2015;12(3):299-306.

3. Hong I, Coker-Bolt P, Anderson KR, Lee D, Velozo CA. Relationship Between Physical Activity and Overweight and Obesity in Children: Findings From the 2012 National Health and Nutrition Examination Survey National Youth Fitness Survey. Am J Occup Ther. 2016;70(5):7005180060p2
4. Eaton SB, Eaton SB. Physical Inactivity, Obesity, and Type 2 Diabetes: An Evolutionary Perspective. Res Q Exerc Sport. 2017;88(1):1-8.

5. Cannioto R, Etter JL, Guterman LB, Joseph JM. The association of lifetime physical inactivity with bladder and renal cancer risk: A hospital-based case-control analysis. Cancer Epidemiol. 2017;49: 24-29.

6. World Health Organization. Global Recommendations On Physical Activity For Health. Geneva. 2010

7. PENSE. Pesquisa Nacional de Saúde do Escolar. Coordenação de Indicadores Sociais, Rio de Janeiro: IBGE, 2015

8. Ha S, Choi HR, Lee YH. Clustering of four major lifestyle risk factors among Korean adults with metabolic syndrome. Plos one. 2017;12: e0174567.

9. Cureau FV, Duarte P, dos Santos DL, Reichert FF. Clustering of Risk Factors for Noncommunicable Diseases in Brazilian Adolescents: Prevalence and Correlates. J Phys Act Heal. 2014;11(5):942-949.

10. Dumith SC, Muniz LC, Tassitano RM, Hallal PC, Menezes AMB. Clustering of risk factors for chronic diseases among adolescents from Southern Brazil. Prev Med. 2012;54(6):393-396.

11. Filho VCB, de Campos W, Lopes AS. Epidemiology of physical inactivity, sedentary behaviors, and unhealthy eating habits among brazilian adolescents. Cien Saúde Colet. 2014;19(1):173-193.

12. Tassitano RM, Dumith SC, Chica DAG, Tenório MCM . Agregamento dos quatro principais comportamentos de risco às doenças não transmissíveis entre adolescentes. Rev Bras Epidemiol. 2014;17(2):465-478.

13. Instituto brasileiro de geografia e estatística. Pesquisa sobre dados demográficos do estado de Sergipe. 2015. Endereço eletrônico: http://www.ibge.gov.br

14. Neto JJS, Karino CA, Jesus GRDe, Andrade DF. A infraestrutura das escolas públicas brasileiras de pequeno porte. Rev do Serviço Público Brasileiro. 2013; 64:377-91.

15. Word Health Organization., Chronic disease and health promotion: global school-based studant health survey (GSHS) purpose and methodology. 2009.

16. Skogen, JC, Silvertsen B, Lundervold A, Stormark KM, Jakobsen R, Hysing M. Alcohol and drug use among adolescents: and the co-occurrence of mental health problems. Ung Hordaland, a population based study. BMJ Open. 2014;4:e005357

17. Malcon MC, Menezes AMB, Chatkin M. Prevalence and risk factors for smoking among adolescents. Rev Saúde Pública. 2003;37(1):1-7.

18. Philippi ST, Latterza AR, Cruz ATR, Ribeiro LC. Pirâmide alimentar adaptada: Guia para escolha dos alimentos. Rev Nutr. 1999;12(1); 65-80.

19. Tremblay MS, Leblanc AG, Janssen I, Kho ME, Hicks A, Murumets $\mathrm{K}$, et al. Canadina sedentary behaviour guidelines for children and youth. Physiol Nutr Metab. 2011 36(1). 59-64.

20. Bard HE, Lakha SF, Pennefather P. Differences in physical activity, eating habits and risk obesity among Kuwaiti adolescent boys and girls: a population-based study. Int J Adolesc Med Health. 2017.

21. Reis RS, Salvo D, Ogilvie D, Lambert E V, Goenka S, Brownson $\mathrm{RC}$, et al. Scaling up physical activity interventions worldwide : stepping up to larger and smarter approaches to get people moving. Lancet. 2016; 6736(10051):1337-1348.

22. Kohl HW, Craig CL, Lambert EV, Inoue S, Alkandari JR, Leetongin G, et al. Physical Activity 5 The pandemic of physical inactivity : global action for. Lancet. 2012;380(9838):294-305. 
23. Filho VCB, Campos W, Lopes A. Prevalence of alcohol and tobacco use among Brazilian adolescents: a systematic review. Rev Saúde Pública. 2012;46(5):901-17.

24. Hallal PC, Andersen LB, Bull FC, Guthold R, Haskell W, Ekelund $\mathrm{U}$, et al. Global physical activity levels : surveillance progress, pitfalls. Lancet. 2012;380(9838):247-57

25. Johnsen NF, Toftager M, Melkevik O, Holstein BE, Rasmussen $\mathrm{M}$. Trends in social inequality in physical inactivity among Danish adolescents 1991-2014. SSM - Popul Heal. 2017;3:534-538.

26. Hecke LV, Loyen A, Verloigne M, van der Ploeg HP, Lakerveld J, Brug J, et al. Variation in population levels of physical activity in European children and adolescents according to cross-European studies: a systematic literature review within DEDIPAC. Int $\mathrm{J}$ Behav Nutr Phys Act. 2016;13(1):70.

27. Poortinga W. The prevalence and clustering of four major lifestyle risk factors in an English adult population. Prev Med. 2007;44(2):124-128.

28. Shuit AJ, Loon AJMV, Tijhuis M, Ocké M. Clustering of lifestyle risk factors in a general adult population. Prev Med. 2002;35(35):219-224.

\section{Corresponding author}

Lucas Souza Santos

Secretária de educação básica do município de Aracaju, Sergipe, Brasil. Endereço: Centro Adminstrativo Prefeito Aloísio Campo, Rua Frei Luís Canelo de Noronha, $n^{\circ}$ 42, CEP 49097-270.

Email: lucas_souzza@hotmail.com

Manuscript received on January 24, 2019

Manuscript accepted on May 10, 2019

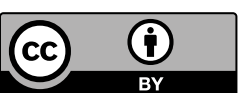

Motriz. The Journal of Physical Education. UNESP. Rio Claro, SP, Brazil - eISSN: 1980-6574 - under a license Creative Commons - Version 4.0 